\title{
CENTRAL PONTINE MYELINOLYSIS IN PATIENTS WITH INADVERTENT INTRAVENOUS FLUID THERAPY: A CASE REPORT SERIES
}

Shweta Gimhavanekar1, Anjali Pawar Dahiphale², Varsha Rote Kaginalkar³, Vinayak Nanekar ${ }^{4}$, Anjali Wasadikar ${ }^{5}$, Ajay Vare ${ }^{6}$

${ }_{13}^{\text {rd }}$ Year Junior Resident, Department of Radiodiagnosis, Government Medical College, Aurangabad.

${ }^{2}$ Associate Professor, Department of Radiodiagnosis, Government Medical College, Aurangabad.

3 Professor \& HOD, Department of Radiodiagnosis, Government Medical College, Aurangabad.

${ }^{4}$ Assistant Professor, Department of Radiodiagnosis, Government Medical College, Aurangabad.

${ }_{5}^{5}$ Associate Professor, Department of Radiodiagnosis, Government Medical College, Aurangabad.

${ }^{6}$ Associate Professor, Department of Radiodiagnosis, Government Medical College, Aurangabad.

\section{ABSTRACT}

Central pontine myelinolysis is an acquired demyelinating disease. It is commonly associated with chronic alcoholics, electrolyte imbalance and chronically debilitated patients. It has predilection for involvement of central portion of basis pontis; however, it may involve axons in the putamina, caudate nuclei, thalami, cerebellum, splenium of the corpus callosum and subcortical white matter.[1] The term "osmotic demyelination syndrome" is similar to "central pontine myelinolysis," but also includes areas outside the pons. ${ }^{[2]}$ It is characterised by loss of myelin and oligodendroglia with relative neuron sparing.

\section{KEYWORDS}

Central Pontine, Osmotic Demyelination.

HOW TO CITE THIS ARTICLE: Gimhavanekar S, Dahiphale AP, Kaginalkar VR, et al. Central pontine myelinolysis in patients with inadvertent intravenous fluid therapy: a case report series. J. Evolution Med. Dent. Sci. 2016;5(38):2356-2358, DOI: $10.14260 /$ jemds/2016/547

\section{INTRODUCTION}

\section{Case 1}

A 22 year primigravida with 5 months of amenorrhoea presented with generalised weakness. She had history of multiple episodes of vomiting since 4 months for which she was treated at primary health centre with IV fluid administration. At the time of admission, her serum potassium (5.9 meq/L) and serum chloride (112.5 meq/L) were slightly increased. She also had anaemia (Hb: $8.3 \mathrm{mg} \%)$. She was managed with IV fluids, antacids and antiemetic medications. Her electrolyte profile improved with the treatment, but her weakness progressed with tingling numbness in all four limbs and slurring of speech. Her USG scan revealed single live intrauterine gestation of 18 weeks. MRI images revealed an area of altered signal intensity in the pons, predominantly central with sparing of the periphery. The lesion was hypointense on T1-Weighted Images (T1WI) and hyperintense on T2WI, FLAIR images with restricted diffusion on DW images (Image 1a \& b).

\section{Case 2}

A 20-years old female with pain in abdomen for 8 months developed sudden weakness and spasms in both lower limbs since 10 days. Her electrolyte profile revealed hyponatremia (102 meq/L) and hypokalemia (2.4 meq/L). She was treated with IV fluids. After 15 days she became drowsy, had dysarthria followed by unconsciousness. She was then referred to MRI, which revealed an area of altered signal intensity in the pons, predominantly central with sparing of the periphery. The lesion was hypointense on T1-weighted

Financial or Other, Competing Interest: None.

Submission 06-03-2016, Peer Review 22-04-2016,

Acceptance 28-04-2016, Published 12-05-2016.

Corresponding Author:

Dr. Vinayak Nanekar

Assistant Professor,

Department of Radiodiagnosis,

Government Medical College,

Aurangabad.

E-mail:vnanekar2005@gmail.com

DOI: $10.14260 /$ jemds/2016/547 images (T1WI) and hyperintense on T2WI, FLAIR images without restricted diffusion. T2W hyperintense signal is also in bilateral caudate nuclei, basal ganglia and thalami. (Fig. 2 \& 3).

\section{Case 3}

A 10-year male was admitted in hospital for pyrexia of unknown cause. On admission his electrolytes were normal (Serum Sodium: $137.9 \mathrm{meq} / \mathrm{L}$, Serum Calcium: $7.9 \mathrm{meq} / \mathrm{L}$ and serum potassium: $4.1 \mathrm{meq} / \mathrm{L})$. CSF examination revealed increase in protein $(80 \mathrm{mg} / \mathrm{dL})$ and decrease in sugar (35 $\mathrm{mg} / \mathrm{dL}$ ). He was diagnosed to have meningitis and was treated with IV fluid and antibiotics. On 10th day of his admission, he became drowsy and had paraparesis. He received $500 \mathrm{~mL}$ NS 8 hourly for 13 days in his course of illness. MRI scan was done on $13^{\text {th }}$ day of admission, which revealed an area of altered signal intensity in the pons, predominantly central with sparing of the periphery. The lesion was hypointense on T1-weighted images (T1WI) and hyperintense on T2WI, FLAIR images without restricted diffusion. Electrolytes done on same day were again within normal limit (Image 4a \& b).

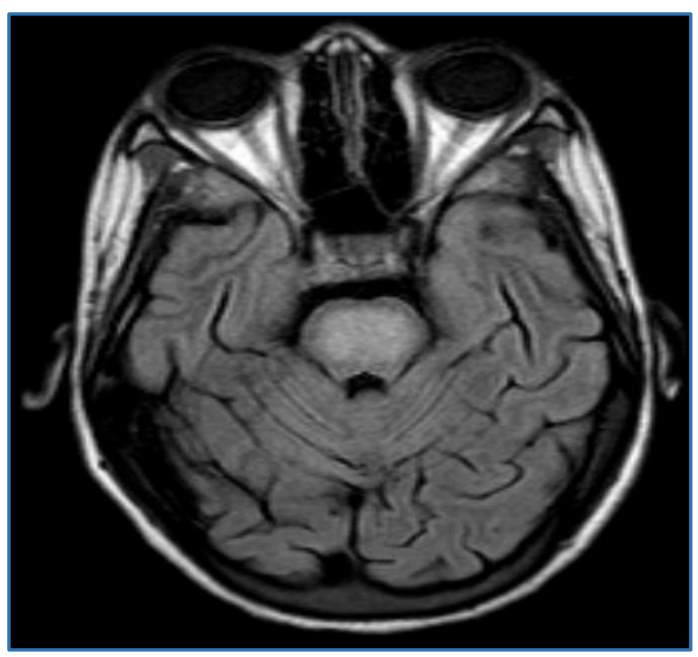

Fig. 1a 


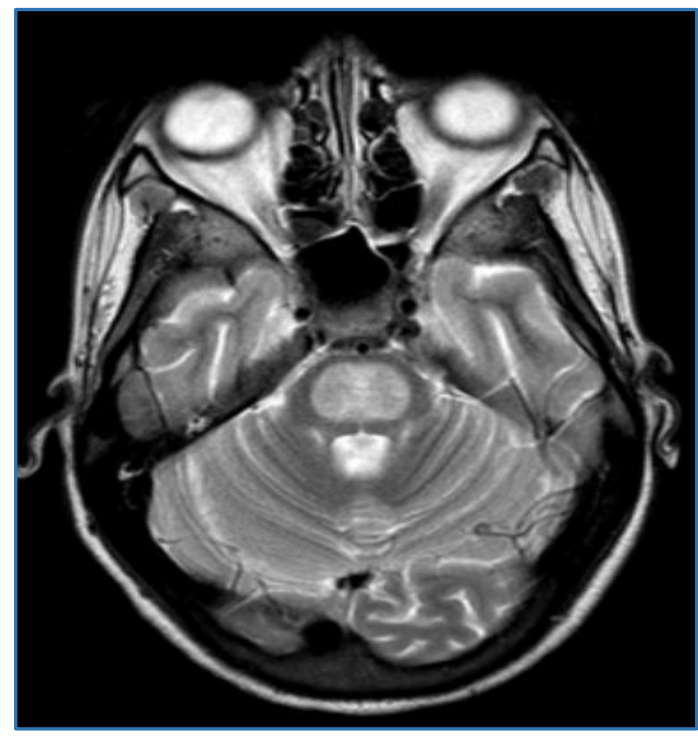

Fig. $1 b$

Fig. 1 ( $a$ \& b): MRI Brain Axial Scans Show Altered Signal Intensity Involving Central Part of Pons. It is Hyperintense on Both FLAIR (Left) and T2W Images (Right)

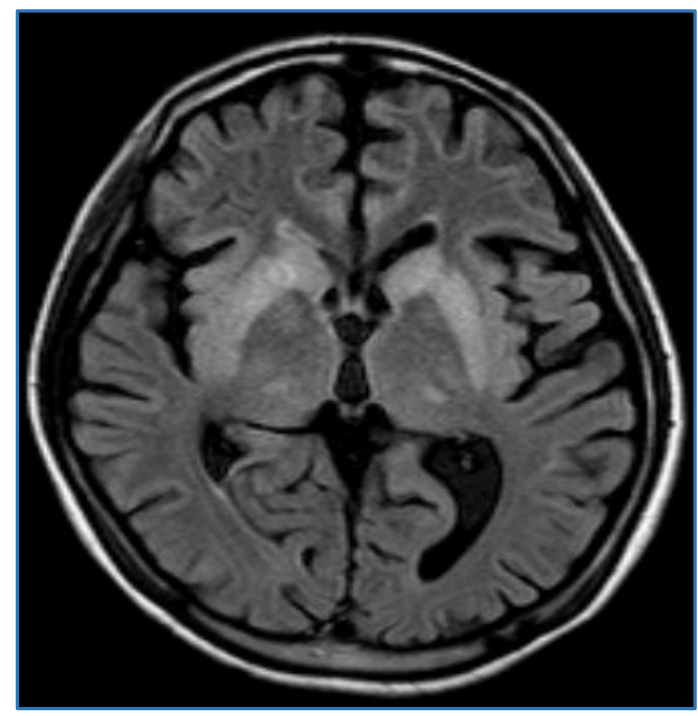

Fig 2: Axial FLAIR Image Showing Extrapontine Hyperintensity in Bilateral Caudate Nuclei, Basal Ganglia \& Thalami

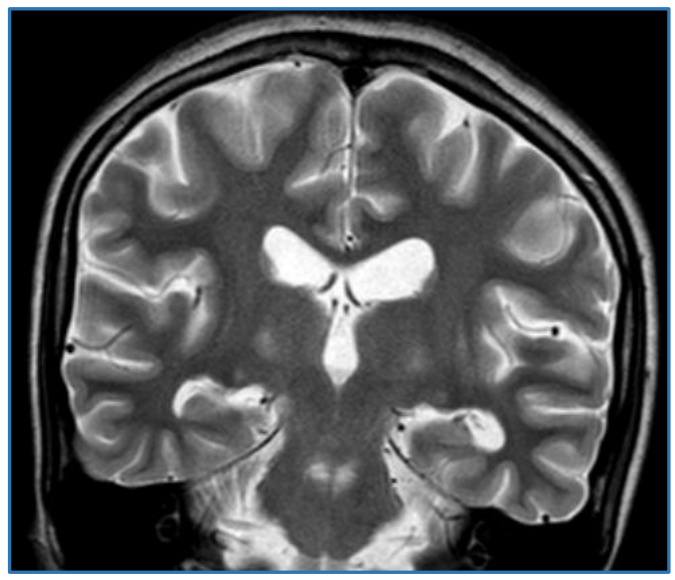

Fig. 3: Coronal T2W Image Showing Hyperintensity in Central Pons

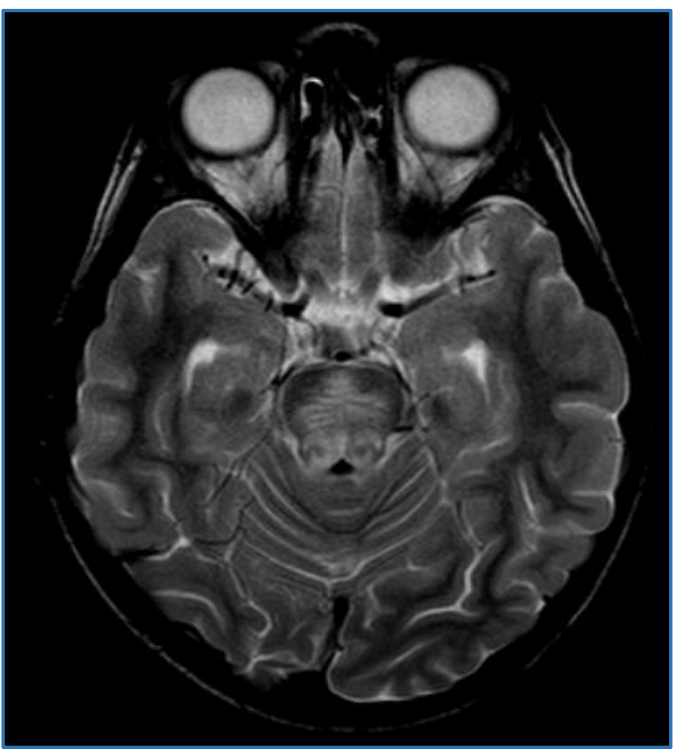

Fig. $4 b$

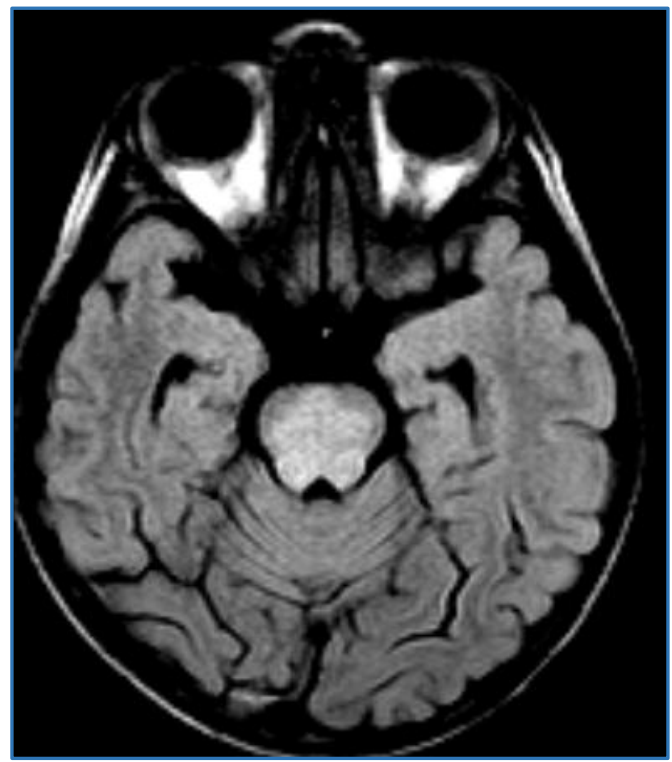

Fig. $4 b$

Fig. 4 a \& b: Axial T2W (Left) \& FLAIR (Right) Image Showing Hyperintense Signal Involving Central Pons

\section{DISCUSSION}

CPM and EPM belong to the osmotic demyelination syndrome (ODS).[3] and are frequently related to the classic context of rapidly corrected hyponatremia.[3], especially in patients who have been chronically debilitated.[4]

Causes of ODS include too rapid correction of low blood sodium levels (hyponatremia).[5], chronic alcoholism.[6], haematopoietic stem cell transplantation.[7], severe liver disease, liver transplant.[8], severe burns.[9], malnutrition, anorexia.[10], severe electrolyte disorders, AIDS, hyperemesis gravidarum.[11], hyponatremia due to Peritoneal Dialysis, Wernicke encephalopathy.[12] Only one of our case had history of hyponatremia. Other two cases were treated with IV fluids for hyperemesis gravidarum and generalised weakness respectively.

The pathophysiological mechanism is unknown. Since both the pontine and extrapontine sites involved have a rich 
grey and white matter interface, it has been hypothesised that a rapid osmotic change causes an endothelial injury in the more vascular grey and white matter, which induces the release of myelinolytic factors that damage the adjacent white matter.[13] The term osmotic myelinolysis is currently favoured for this condition.

ODS may occur when serum sodium levels are normal.[14] or high and even if serum sodium levels are corrected within safe limits.[15] Two of our patients had normal electrolyte levels.

The initial symptoms may be weakness, confusion and dysarthria. In severe cases, there is spastic quadriparesis and pseudobulbar palsy. This may evolve within 3-10 days into a locked-in-state (pseudo coma). Death within 2-3 months is the usual outcome. The 6-month survival rate is $5-10 \%$. Recovery may be spontaneous and progressive, sometimes without any neurological sequelae.[14] All three of our patients showed improvement with some residual paraparesis.

Apparently, there is no correlation between clinical signs and symptoms and the persistence of lesions on neuroimaging exams.[16] as well as between extent of lesions on MRI and clinical severity of subsequent presentation or clinical outcome.[16] Abnormal radiological results may be found despite evident clinical improvement or after resolution of clinical symptoms or else they may resolve despite the presence of clinical neurological symptoms.[16]

The imaging features are due to increased water content in the affected areas. Transverse pontine fibres are more severely affected compared with descending cortico-spinal tracts. NECT scans are normal or disclose nonspecific hypodense areas. Lesions appear hypointense on T1WI and hyperintense on T2WI and show varied enhancement following contrast administration.[13]

Differential diagnosis of central pontine myelinolysis includes infarct, metastasis, glioma, multiple sclerosis, encephalitis, radiotherapy and chemotherapy.[15]

\section{CONCLUSION}

Central pontine myelinolysis is a rare clinical diagnosis. Classic history of hyponatremia or its rapid correction may not always be present. In such cases, high degree of clinical suspicion is necessary. MRI is the investigation of choice, which shows classic involvement of central pons with or without extrapontine involvement.

\section{REFERENCES}

1. Bourgouin PM, Chalk C, Richardson J, et al. Subcortical white matter lesions in osmotic demyelination syndrome. AJNR Am J Neuroradiol 1995;16:1495-1497.

2. Lampl C, Yazdi K. Central pontine myelinolysis. Eur Neurol 2002;47(1):3-10. doi:10.1159/000047939.
3. Martin RJ. Central pontine and extra-pontine myelinolysis: the osmotic demyelination syndromes. J Neurol Neurosurg Psychiatry 2004;75(suppl III):iii22-8.

4. Pradhan S, Jha R, Singh MN, et al. Central pontine myelinolysis following slow correction of hyponatremia. Clin Neurol Neurosurg 1995;97(4):340-3.

5. Bernsen HJ, Prick MJ. Improvement of central pontine myelinolysis as demonstrated by repeated magnetic resonance imaging in a patient without evidence of hyponatremia. Acta Neurol Belg 1999;99(3):189-93.

6. Yoon B, Shim YS, Chung SW. Central pontine and extrapontine myelinolysis after alcohol withdrawal. Alcohol 2008;43(6):647-9. doi:10.1093/alcalc/agn050.

7. Lim KH, Kim S, Lee YS, et al. Central pontine myelinolysis in a patient with acute lymphoblastic leukaemia after haematopoietic stem cell transplantation: a case report. J Korean Med Sci 2008;23(2):324-7. doi:10.3346/jkms.2008.23.2.324.

8. Singh N, Yu VL, Gayowski T. Central nervous system lesions in adult liver transplant recipients: clinical review with implications for management. Medicine (Baltimore) 1994;73(2):110-8. doi:10.1097/00005792-19940300000004.

9. McKee AC, Winkelman MD, Banker BQ. Central pontine myelinolysis in severely burned patients: relationship to serum hyperosmolality. Neurology 1988;38(8):1211-7. doi:10.1212/wnl.38.8.1211.

10. Sugimoto T, Murata T, Omori $\mathrm{M}$, et al. Central pontine myelinolysis associated with hypokalaemia in anorexia nervosa. J Neurol Neurosurg Psychiatr 2003;74(3):353-5. doi:10.1136/jnnp.74.3.353.

11. Bergin PS, Harvey P. Wernicke's encephalopathy and central pontine myelinolysis associated with hyperemesis gravidarum. BMJ 1992;305(6852):517-8. doi:10.1136/bmj.305.6852.517.

12. Kishimoto Y, Ikeda K, Murata K, et al. Rapid development of central pontine myelinolysis after recovery from Wernicke encephalopathy: a non-alcoholic case without hyponatremia. Intern Med 2012;51(12):1599-603. doi:10.2169/internalmedicine.51.7498.

13. Koragi Y, Takahashi M, Shinzaho J, et al. MR findings in two presumed cases of mild central pontine myelinolysis. Am J Neuoradiol 1995;14:651-654.

14. Lilje CG, Heinen F, Laubenberger J, et al. Benign course of central pontine myelinolysis in a patient with anorexia nervosa. Paediatr Neurol. 2002;27(2):132-5.

15. Miller GM, Baker HL, Okozaki H, et al. Central pontine myelinolysis and its imitators: MR findings. Radiology 1988;168(3):795-802.

16. Menakaya JO, Wassmer E, Bradshaw K, et al. Idiopathic central pontine myelinolysis in childhood. Dev Med Child Neurol 2001;43(10):697-700. 